\title{
Ultra Fine-Grained Metals Prepared by Severe Plastic Deformation: A Positron Annihilation Study
}

\author{
J. ČÍŽEK ${ }^{a}$, I. ProcházKA ${ }^{a}$, R. KuŽEL ${ }^{a}$, Z. MATĚJ ${ }^{a}$, \\ V. Cherkaska ${ }^{a}$, M. $\operatorname{Cieslar}^{a}$, B. Smola ${ }^{a}$, I. Stulíkováa $^{a}$,

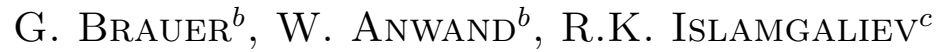 \\ AND O. Kulyasova ${ }^{c}$
}

${ }^{a}$ Faculty of Mathematics and Physics, Charles University in Prague V Holešovičkách 2, 18000 Praha 8, Czech Republic

${ }^{b}$ Institut für Ionenstrahlphysik und Materialforschung

Forschungszentrum Rossendorf, Dresden, Germany

${ }^{c}$ Institute of Physics of Advanced Materials

Ufa State Aviation Technical University, Ufa, Russia

\begin{abstract}
Recent investigations of ultra fine-grained metals $(\mathrm{Cu}, \mathrm{Fe}, \mathrm{Ni})$ performed within a Prague-Rossendorf-Ufa collaboration will be reviewed. The specimens were prepared by severe plastic deformation: the high-pressure torsion and equal channel angular pressing. Positron annihilation spectroscopy was used as the main method including (i) the conventional lifetime and the Doppler broadening measurements with ${ }^{22} \mathrm{Na}$ and (ii) the slow-positron implantation spectroscopy with the Doppler broadening measurement. Other methods were also involved: transmission electron microscopy, X-ray diffraction, and microhardness. First, the mean grain size was determined and defects were identified in the as-deformed materials. Defects concentration and spatial distribution were studied in detail. Dislocations situated in distorted regions along grain boundaries, and a few-vacancy clusters distributed homogeneously inside dislocations-free grains, were observed in the ultra fine-grained $\mathrm{Cu}, \mathrm{Fe}$, and Ni. Subsequently, the thermal evolution of the ultra fine-grained structures during isochronal annealing was studied.
\end{abstract}

PACS numbers: 78.70.Bj, 79.60.Jv 


\section{Introduction}

Over the past several decades it has become known that the refinement of grain size of the traditional polycrystalline metals below one micrometer can lead to a significant improvement of their mechanical, electrical, thermal, and other properties. This is why ultra fine-grained (UFG) metals, which are characterised with a mean grain size of several hundreds of nanometers, are nowadays attracting much attention of materials researchers as promising materials for various industrial applications. Among the methods of production of the UFG metals, those based on severe plastic deformation (SPD) are of a great importance, see Refs. [1,2] for a review. Macroscopic amounts of UFG materials with no porosity can be obtained by means of SPD. The following important elements of the SPD-created UFG structures can be outlined:

(i) Grains of the size of several hundreds of nanometers, which becomes comparable to typical diffusion lengths of free positrons in metals $(\approx 100 \mathrm{~nm})$.

(ii) Grain boundaries (GB) whose integrated volume constitutes, contrary to the ordinary polycrystalline metals, a significant fraction of the total volume of the material.

(iii) Defects introduced by SPD (dislocations, vacancies and vacancy clusters, GBs).

The two techniques utilising SPD have recently been introduced to produce UFG structures in a wide class of metallic systems [2]:

(a) The high-pressure torsion (HPT) is a technique capable to provide disk-shaped specimens of the diameter of $\approx 10 \mathrm{~mm}$ and thickness of $0.2 \div 0.5 \mathrm{~mm}$. The HPT-made specimens exhibit rather small grain size of $\approx 100 \mathrm{~nm}$, homogeneous UFG structure, and a weak texture only.

(b) The equal channel angular pressing (ECAP) can produce more massive specimens, however, the mean grain size usually appears to be larger compared to HPT.

SPD process results in a highly non-equilibrium structure. It seems obvious that defects play a key role in formation of the UFG structure and lie beneath the extraordinary properties of these materials. Detailed defect investigations become thus highly desirable from the point of understanding the formation and thermal stability of the UFG structures. Positron annihilation spectroscopy (PAS) is a powerful non-destructive technique of microstructural studies of a variety materials [3]. It appears to be extremely sensitive to the small-sized open-volume defects. PAS thus seems to be an ideal tool for the investigation of the above listed UFG structure elements.

In the present lecture, recent investigations of the HPT-prepared UFG metals, performed within a Prague-Rossendorf-Ufa collaboration, will be reviewed. PAS was utilised as the principal experimental technique including: 
(i) the conventional lifetime and the Doppler broadening (DB) measurements with ${ }^{22} \mathrm{Na}$ positron source and

(ii) the slow-positron implantation spectroscopy (SPIS) with DB measurements.

Other experimental methods, complementary to PAS, were also involved in these investigations: the transmission electron microscopy (TEM), X-ray diffraction (XRD), and microhardness measurements. The present lecture will concentrate on the results obtained for the $\mathrm{Cu}$, Fe, Ni UFG metals and $\mathrm{Cu}+\mathrm{Al}_{2} \mathrm{O}_{3}$ composite. The Mg-based UFG metallic systems have been studied within the above collaboration, too. These results are presented elsewhere at this Conference [4].

\section{Experiments}

\subsection{Specimens}

The UFG specimens dealt with here are listed in the first column of Table. The HPT-made specimens of the UFG $\mathrm{Cu}, \mathrm{Fe}$, Ni metals and $\mathrm{Cu}+\mathrm{Al}_{2} \mathrm{O}_{3}$ composite were prepared at room temperature (RT) by a technique described in Ref. [2]. Torsion was performed up to a true logarithmic strain of $\varepsilon=7$ under a high pressure of $6 \mathrm{GPa}$. A set of the UFG $\mathrm{Cu}$ specimens deformed under a pressure of $3 \mathrm{GPa}$ was prepared, too. All the HPT-made specimens were disk-shaped with a diameter of $10 \div 12 \mathrm{~mm}$ and thickness of $0.2 \div 0.4 \mathrm{~mm}$. A set of the UFG $\mathrm{Cu}$ specimens prepared by the ECAP technique [2] (route Bc, i.e. the pressed sample is rotated by $90^{\circ}$ after each pass, 12 passes, RT) was also involved in the present investigations.

\section{TABLE}

Positron lifetimes $\tau_{i}$ and relative intensities $I_{i}(i=1,2)$ observed in as-deformed UFG samples. The errors (one standard deviation) are given in parentheses in units of the last significant digits. Symbol $n_{\mathrm{V}}$ denotes number of vacancies constituting vacancy clusters (microvoids), see the text for details.

\begin{tabular}{l|c|c|c|c|c}
\hline \hline \multicolumn{1}{c|}{ Sample } & $\tau_{1}[\mathrm{ps}]$ & $I_{1}[\%]$ & $\tau_{2}[\mathrm{ps}]$ & $I_{2}[\%]$ & $n_{\mathrm{V}}$ \\
\hline HPT deformed $\mathrm{Cu}, p=6 \mathrm{GPa}$ & $161(3)$ & $64(4)$ & $249(5)$ & $36(4)$ & $4.8(3)$ \\
HPT deformed $\mathrm{Cu}, p=3 \mathrm{GPa}$ & $164(1)$ & $83(4)$ & $255(4)$ & $17(3)$ & $5.2(3)$ \\
HPT deformed $\mathrm{Cu}+0.5$ wt.\% & $161(3)$ & $60.4(5)$ & $257(1)$ & $39.6(5)$ & $5.31(7)$ \\
$\quad \mathrm{Al}_{2} \mathrm{O}_{3}$ (GlidCop), $p=6 \mathrm{GPa}$ & & & & & \\
ECAP deformed Cu, & $164(3)$ & $80(6)$ & $240(10)$ & $20(6)$ & $4.2(6)$ \\
$\quad$ route Bc, $12 \mathrm{passes}$ & & & & & \\
HPT deformed Ni, $p=6 \mathrm{GPa}$ & $157(1)$ & $88.9(6)$ & $336(8)$ & $11.1(6)$ & $13.1(6)$ \\
HPT deformed $\mathrm{Fe}, p=6 \mathrm{GPa}$ & $150.9(4)$ & $90.6(3)$ & $352(6)$ & $9.5(3)$ & $13.2(5)$
\end{tabular}




\subsection{Apparatus}

Conventional PAS. A $\mathrm{BaF}_{2}$ lifetime spectrometer described in Ref. [5] was employed in the course of present work. The spectrometer exhibited a time resolution of $150 \div 170 \mathrm{ps}$ (FWHM) for ${ }^{22} \mathrm{Na}$ and a coincidence count rate of $\approx 100$ coincidence events per second. A carrier-free ${ }^{22} \mathrm{NaCl}$ (Amersham) positron source of $\approx 1.5 \mathrm{MBq}$ strength sealed between $2 \mu \mathrm{m}$ mylar D foils (DuPont) was used. The diameter of radioactive spot was $\approx 3 \mathrm{~mm}$. At least $10^{7}$ counts were collected in each lifetime spectrum. The measured spectra were decomposed in up to five exponential components (including $\approx 7 \%$ contribution arising from annihilation in the source) using the maximum likelihood procedure [5]. The conventional DB measurements were performed with a HPGe detector (1.7 keV FWHM at $511 \mathrm{keV})$.

SPIS. SPIS measurements were performed on the magnetically guided positron beam facility "SPONSOR" at FZ Rossendorf [6]. Line shapes of annihilation $\gamma$-rays were measured with a HPGe detector having an energy resolution (FWHM) of $1.09 \mathrm{keV}$ at $511 \mathrm{keV}$. The beam diameter at the sample surface was $\approx 4 \mathrm{~mm}$. The dependences of annihilation line shape parameters $S$ on positron energy $E$ were measured in the interval $E=30 \mathrm{eV} \div 35 \mathrm{keV}$ and analysed by means of the VEPFIT code [7].

Other methods. TEM observations were performed using a JEOL 2000 FX electron microscope operating at $200 \mathrm{kV}$. XRD investigations were carried out on XRD7 and HZG4 (Seifert-FPM) powder diffractometers using $\mathrm{Cu} K_{\alpha}$ radiation. The microhardness $H_{\mathrm{V}}$ was measured by the Vickers method by means of a LECO M-400-A hardness tester with a load of $100 \mathrm{~g}$ applied for $10 \mathrm{~s}$.

\section{Results and discussion}

In this section, the main results obtained on SPD-prepared UFG $\mathrm{Cu}, \mathrm{Ni}, \mathrm{Fe}$ and $\mathrm{Cu}+\mathrm{Al}_{2} \mathrm{O}_{3}$ will be briefly presented while the details of these investigations have been given elsewhere [8-13].

\subsection{Characterisation of as-deformed UFG specimens}

All the UFG materials listed in Table exhibited two lifetime components. Corresponding lifetimes $\tau_{i}$ and intensities $I_{i}(i=1,2)$ were shown in columns 2 thru 5 of Table. As the measured lifetimes significantly exceed the respective bulk ones, both the observed components come from positrons trapped at defects. Thus saturated positron trapping takes place in the as-deformed specimens indicating high defect densities created by SPD.

The dominating component with the shorter lifetime $\tau_{1}$ is slightly lower than the lifetimes of positrons trapped in monovacancies in respective materials which is typical of positron trapping at dislocations. For example, the lifetimes for monovacancies in $\mathrm{Cu}$ and $\mathrm{Ni}$ were observed [14] to be of $168-170 \mathrm{ps}$, i.e. by about $10 \mathrm{ps}$ 
higher than present values of $\tau_{1}$. Indeed, TEM observations on UFG $\mathrm{Cu}, \mathrm{Ni}$ and Fe performed within present investigations revealed a strongly non-uniform spatial distribution of dislocations: grain interiors almost free of dislocations separated by distorted regions along GBs with a high dislocation density. Hencefore, one concludes that $\tau_{1}$-component in the UFG materials of Table arises from positrons trapped at dislocations situated in the distorted regions along GBs. However, this cannot be regarded as a general conclusion because, as reported at this Conference [4], a uniform distribution of dislocations was found in the HPT-processed UFG $\mathrm{Mg}-10 \% \mathrm{Gd}$ alloy. As it was discussed in Ref. [4], the uniform spatial distribution of dislocations seems to be present predominantly in HPT-deformed metals with the hcp structure as a consequence of a lower number of slip systems compared to the fcc and bcc metals.

The longer lifetime $\tau_{2}$ represents a contribution of positrons trapped in vacancy clusters referred to as microvoids below. The formation of vacancy clusters in these materials is to be considered here since a large number of vacancies are created during SPD. Vacancies are mobile at RT in the metals under study [15] so that they can diffuse to sinks at GBs, decorate dislocations present in the sample and a portion of vacancies can form small vacancy clusters. The latter process obviously becomes more likely inside the dislocation-free grain interiors as it appeared to be suppressed in HPT-deformed $\mathrm{Mg}-10 \% \mathrm{Gd}$ alloy with homogeneously distributed dislocations [4]. The average size of vacancy clusters, i.e. an average number of vacancies $n_{\mathrm{V}}$ constituting the clusters, was estimated from the comparison of the measured lifetime $\tau_{2}$ with that calculated ab initio on the basis of the density functional theory. Details of such calculations for $\mathrm{Cu}, \mathrm{Ni}$, and Fe were given elsewhere $[8,10,16]$ and the results were included in the last column of Table. The intra-comparison of the $n_{\mathrm{V}}$-values shown in Table suggests a conclusion that the size of microvoids depends primarily on the material under question (through the different mobility of vacancies in different metals) and its dependence on the deformation method is of less importance [12].

\subsection{Spatial distribution of defects}

Since a key role of defects in the formation and properties of UFG structures is obvious, spatial distribution of defects resulting from HPT deformation may serve as a valuable test of optimum parameters of the deformation process. Spatial distribution of defects was investigated on the UFG $\mathrm{Cu}$ specimen, produced by HPT at 6 GPa, by means of SPIS and conventional PAS supplemented by TEM, XRD, and microhardness measurements [11, 13]. In order to obtain depth dependence of defect density at a larger depth scale the specimen was subjected to a controlled chemical etching. The $S$-parameter values corresponding to positron annihilation in the bulk were found to decrease gradually up to an $18 \mu \mathrm{m}$ layer removed by etching. Then, no further decrease in $S$-values in the bulk was observed. Since the decrease in $S$ indicates a corresponding decrease in defect 
density, one can conclude that the concentration of defects decreases with depth in a surface layer of $\approx 18 \mu \mathrm{m}$ thickness and at deeper layers remains unchanged. This decrease comes primarily from the decrease in concentration of microvoids with depth and also from a slight increase in grain size with depth suggested by XRD investigations (see Ref. [11] for details).

Radial dependence of defect concentrations was also inspected by PAS and SPIS. The following main results were obtained [11]:

- There is no radial change in the mean grain size, a value of $120 \pm 20 \mathrm{~nm}$ being measured by TEM. This is in reasonable agreement with XRD findings. Also the dislocation density was found by XRD to remain unchanged with radial distance from the centre of disk.

- On the other hand, it was found that size and density of microvoids vary with the radial distance from the centre of the sample.

\subsection{Thermal stability of UFG structure}

The investigation of the thermal stability of the UFG structures can contribute to understanding the physical processes in the UFG metals, but is also important from the point of view of the industrial application of these materials. Isochronal annealing curves were measured on HPT-made UFG $\mathrm{Cu}$ (two specimens prepared under 3 and $6 \mathrm{GPa}$ pressure) and $\mathrm{Cu}+\mathrm{Al}_{2} \mathrm{O}_{3}$. The difference in the pressure resulted in a difference in the mean grain size of the UFG $\mathrm{Cu}$ specimens, as measured by TEM: 150 and $105 \mathrm{~nm}$, respectively. Annealing steps were $30^{\circ} \mathrm{C}$. Specimens were annealed for $30 \mathrm{~min}$ at each temperature. Each annealing step was finished by quenching to water of room temperature. In Fig. 1, the

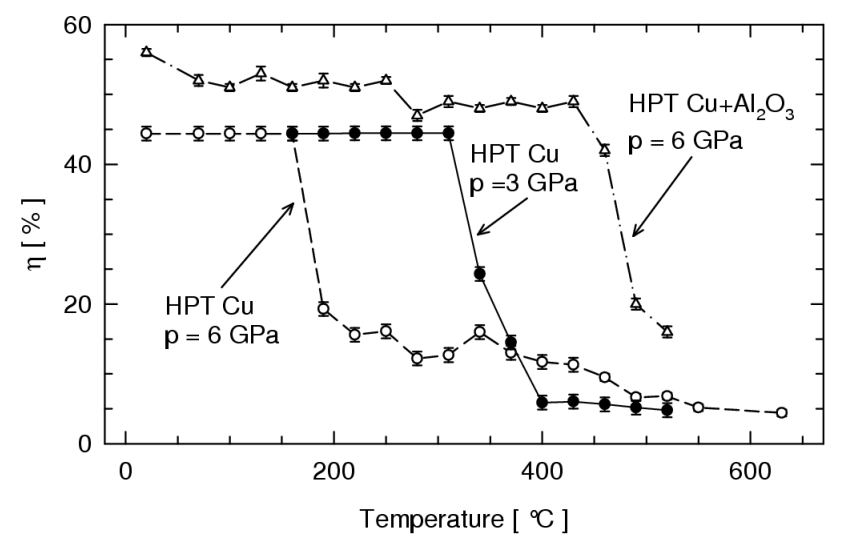

Fig. 1. The thermal evolution of volume fraction $\eta$ of distorted regions along GBs with annealing temperature as obtained from the analysis of positron lifetime data within the diffusion trapping model [8]: UFG $\mathrm{Cu}$ (6 GPa) - open circles, UFG $\mathrm{Cu}$ $(3 \mathrm{GPa})$ - filled circles and UFG $\mathrm{Cu}+0.5$ wt.\% $\mathrm{Al}_{2} \mathrm{O}_{3}$ composite - open triangles. 
temperature dependence of the volume fraction $\eta$ of distorted regions along GBs, deduced for UFG $\mathrm{Cu}(3 \mathrm{GPa})$ and $\mathrm{Cu}+\mathrm{Al}_{2} \mathrm{O}_{3}$ from PAS data using the diffusion trapping model [8], is compared with UFG $\mathrm{Cu}$ (6 GPa). We can outline here the main results of these annealing experiments (see Refs. [8, 10, 11] for details):

- In both $\mathrm{Cu}$ specimens, the recovery of the UFG structure is realised by the same processes. The abnormal grain growth when isolated recrystallised grains appear in virtually unchanged deformed matrix is followed at higher temperatures by recrystallisation in the whole volume of the specimen.

- The recrystallisation process was found to start around $300^{\circ} \mathrm{C}$ in HPT-deformed $\mathrm{Cu}$ under $3 \mathrm{GPa}$ (mean grain size of $150 \mathrm{~nm}$ ). In the case of the HPT $\mathrm{Cu}$, deformed under $6 \mathrm{GPa}$ (finer grains of $105 \mathrm{~nm}$ size), the start of recrystallisation is moved to about $200^{\circ} \mathrm{C}$, i.e. by about $100^{\circ} \mathrm{C}$ towards lower temperatures (see Fig. 1).

- Activation energy of recrystallisation in the UFG $\mathrm{Cu}$, deduced from the present annealing experiments, corresponds reasonably well with the activation energy of migration of the equilibrium grains in the coarse-grained $\mathrm{Cu}$.

- The same sequence of recrystallisation processes as in the UFG $\mathrm{Cu}$ appears also in UFG $\mathrm{Cu}+\mathrm{Al}_{2} \mathrm{O}_{3}$ composite, however, the temperature region of recrystallisation is shifted by almost $300^{\circ} \mathrm{C}$ towards higher temperatures in the composite with respect to UFG $\mathrm{Cu}(6 \mathrm{GPa})$, see Fig. 1.

\section{Summary}

UFG structures in $\mathrm{Cu}, \mathrm{Fe}, \mathrm{Ni}$ metals, and $\mathrm{Cu}+0.5$ wt. $\% \mathrm{Al}_{2} \mathrm{O}_{3}$ composite processed by SPD were studied in detail by means of PAS techniques in combination with TEM, XRD, and microhardness measurement. Defects were identified and their concentrations and spatial distributions were investigated. Dislocations situated in distorted regions along GBs and small vacancy clusters distributed homogeneously inside dislocation-free grain interiors were observed. In the HPT-made $\mathrm{Cu}$, the size and density of vacancy clusters were found to vary with depth and radial distance from the sample centre. Thermal stability of the UFG structure was shown to be influenced by the average grain size in the as-deformed material. The $\mathrm{Al}_{2} \mathrm{O}_{3}$ nanoparticles were shown to improve thermal stability of the HPT made $\mathrm{Cu}$.

\section{Acknowledgments}

This work was partially supported by the Czech Ministry of Education, Youths, and Sports under contracts COST OC523.50, 1K03025 and KONTAKT 
ME0556. Support from The Grant Agency of Czech Republic (project GA 106/01/D049) is also acknowledged.

\section{References}

[1] Nanomaterials by Severe Plastic Deformation, Proc. Conf. "Nanomaterials by Severe Plastic Deformation - NANOSPD2", Vienna 2002, Eds. M. Zehetbauer, R.Z. Valiev, Wiley-VCH Verlag GmbH\&Co. KgaA, Weinheim 2004.

[2] R.Z. Valiev, R.K. Islamgaliev, I.V. Aleksandrov, Prog. Mater. Sci. 45, 103 (2000).

[3] P. Hautojärvi, C. Corbel, in: Positron Spectroscopy of Solids, Proc. Int. School of Physics "Enrico Fermi", Course CXXV, Eds. A. Dupasquier, A.P. Mills, Jr., Varenna (Italy) 1993, IOS Press, Amsterdam 1995, p. 491.

[4] J. Č́̌žek, I. Procházka, B. Smola, I. Stulíková, R. Kužel, Z. Matěj, V. Cherkaska, R.K. Islamgaliev, O. Kulyasova, Acta Phys. Pol. A 107, 738 (2005).

[5] F. Bečváŕ, J. Čížek, L. Lešt'ak, I. Novotný, I. Procházka, F. Šebesta, Nucl. Instrum. Methods Phys. Res. A 443, 557 (2000).

[6] W. Anwand, H.-R. Kissener, G. Brauer, Acta Phys. Pol. A 88, 7 (1995).

[7] A. van Veen, H. Schut, M. Clement, J. de Nijs, A. Kruseman, M. Ijpma, Appl. Surf. Sci. 85, 216 (1995).

[8] J. Č́́žek, I. Procházka, M. Cieslar, R. Kužel, J. Kuriplach, F. Chmelik, I. Stulíková, F. Bečváŕ, O. Melikhova, Phys. Rev. B 65, 094106 (2000).

[9] J. Č́žzek, I. Procházka, G. Brauer, W. Anwand, R. Kužel, M. Cieslar, R.K. Islamgaliev, Phys. Status Solidi A 195, 335 (2003).

[10] J. Čížek, I. Procházka, M. Cieslar, I. Stulíková, F. Chmelik, R.K. Islamgaliev, Phys. Status Solidi A 191, 391 (2002).

[11] J. Čížek, I. Procházka, R. Kužel, R.K. Islamgaliev, Chem. Monthly 133, 873 (2002).

[12] J. Čížek, I. Procházka, B. Smola, I. Stulíková, R. Kužel, M. Cieslar, Z. Matěj, V. Cherkaska, G. Brauer, W. Anwand, R.K. Islamgaliev, O. Kulyasova, Mater. Sci. Forum 482, 207 (2005).

[13] J. Č́̌žek, I. Procházka, R. Kužel, M. Cieslar, I. Stulíková, in Ref. [1], p. 630.

[14] T.E.M. Staab, R. Kause-Rehberg, B. Kieback, J. Mater. Sci. 34, 3833 (1999).

[15] A. van den Beukel, in: Proc. Int. Conf. on Vacancies and Interstitials in Metals, Eds. A. Seeger, D. Schumacher, W. Schilling, J. Diehl, North-Holland, Amsterdam 1970, p. 427.

[16] A. Hempel, A. Saneyasu, Z. Tang, M. Hasegawa, G. Brauer, F. Plazaola, S. Yamaguchi, in: Effects of Radiation on Materials, 19th Int. Symp. ASTM STP 1366, Eds. A.B. Smith, C.D. Jones, American Society for Testing Materials, West Conshohocken 1998, p. 132. 